\title{
Sub-Minute Method for Determination of Naphazoline in the Presence of Diphenhydramine, Pheniramine or Chlorpheniramine by Capillary Electrophoresis
}

\author{
Michelle M. A. C. Ribeiro, ${ }^{a}$ Mariana C. Marra, ${ }^{a}$ Brenda M. C. Costa, ${ }^{a}$ Thiago C. Oliveira, ${ }^{a}$ \\ Alex D. Batista, ${ }^{a}$ Rodrigo A. A. Muñoz $z^{a}$ and Eduardo M. Richter $*, a$ \\ anstituto de Química, Universidade Federal de Uberlândia, \\ Av. João Naves de Ávila, 2121, 38400-902 Uberlândia-MG, Brazil
}

\begin{abstract}
This paper presents a simple and low-cost capillary electrophoresis method for ultra-fast simultaneous determination of naphazoline (NPZ) and one of the following active ingredients: diphenhydramine (DIP), pheniramine (PHEN) or chlorpheniramine (CPHEN). The proposed method is based on capillary electrophoresis with capacitively coupled contactless conductivity detection $\left(\mathrm{CE}-\mathrm{C}^{4} \mathrm{D}\right)$ equipped with a short length capillary column $(10 \mathrm{~cm})$. One sample can be analyzed every $35 \mathrm{~s}$ (ca. 100 injections per hour) with resolutions between peaks greater than 1.4. The optimized background electrolyte (BGE) was composed by $20 \mathrm{mmol} \mathrm{L}^{-1}$ histidine and $10 \mathrm{mmol} \mathrm{L}^{-1}$ 3,4-dimethoxycinnamic acid ( $\mathrm{pH}=9.5$, adjusted with $\left.\mathrm{NaOH}\right)$. Limits of detection were $25 \mu \mathrm{mol} \mathrm{L}{ }^{-1}$ for NPZ, DIP, and PHEN and $13 \mu \mathrm{mol} \mathrm{L} \mathrm{L}^{-1}$ for CPHEN. The results obtained with the developed procedure were compared to those obtained by high-performance liquid chromatography (HPLC) and no statistically significant differences were observed (95\% confidence level).
\end{abstract}

Keywords: short length column, sub-minute separation, quality control, antihistamines, imidazole derivative

\section{Introduction}

Naphazoline (NPZ) is an active ingredient used in over-the-counter eye and nasal preparations. ${ }^{1}$ This drug is a long-lasting vasoconstrictor that is generally used as a topical nasal or ocular decongestant. ${ }^{2,3}$ Its field of action is increased by combining it with other active ingredients in the same formulation (synergistic effects), e.g. diphenhydramine hydrochloride (DIP), ${ }^{4,5}$ pheniramine maleate (PHEN) ${ }^{6}$ or chlorpheniramine maleate (CPHEN) ${ }^{7,8}$ NPZ in combination with DIP is effective in relieving flu symptoms, such as nasal obstruction, runny nose and sneezing. ${ }^{9}$ The combination of NPZ with PHEN or CPHEN is commonly used as ophthalmic solution, due to the NPZ vasoconstrictor effect that improves the beneficial effects of PHEN or CPHEN (relief of redness, burning, irritation and dryness of the eyes)..$^{10,11}$

Pharmaceutical formulations containing NZP + DIP, $\mathrm{NPZ}+$ PHEN or NPZ + CPHEN are very popular and easily accessible, and therefore, are widely consumed around the world. For this reason, the development of fast, simple, low cost and environmentally friendly analytical

*e-mail: emrichter@ufu.br methods for quality control of these drugs is desirable. Thus far, some analytical methods were reported for the simultaneous determination of NPZ and DIP, such as capillary electrophoresis (CE) with UV-Vis detection, ${ }^{12}$ second-order derivative UV spectroscopy,${ }^{13,14}$ first-order derivative UV-spectroscopy, ${ }^{15}$ and non-aqueous titration. ${ }^{16}$ For simultaneous determination of NPZ and CPHEN, two methods employing chemometric and derivative spectrophotometry were reported, ${ }^{8,17}$ and for simultaneous determination of NPZ and PHEN, only one method based on high-performance liquid chromatography (HPLC) with UV-Vis detection was reported. ${ }^{11}$ However, most of the described methods require expensive instrumentation or is time-consuming, which is undesirable in quality control activities.

Capillary electrophoresis with capacitively coupled contactless conductivity detection $\left(\mathrm{CE}-\mathrm{C}^{4} \mathrm{D}\right)^{18,19}$ is a technique based on the migration and separation of charged species under the effects of a high electric field. ${ }^{20,21} \mathrm{C}^{4} \mathrm{D}$ is a universal conductivity detector for small inorganic ions as well as organic and biochemical species, in which the electrodes are not in direct contact with the solution..$^{22-24}$ The detection of charged species is based on the conductivity difference between the background electrolyte (BGE) 
solution and the charged analytes. The popularity of the $C^{4} D$ detector in $C E$ systems has increased due to its characteristics such as robustness, minimal maintenance demands, low cost, and the possibility of detection of species with low and high molar attenuation coefficients in a single run. ${ }^{25-29}$

High-throughput methods are desirable especially for quality control routine analysis. Capillary electrophoresis fulfils this requirement due to the use of a short capillary column that provides fast and efficient analyte separation. ${ }^{30,31}$ In addition to the significant reduction in analysis time, an increase in sensitivity can also be achieved (shorter time for diffusion-concentration profiles). This approach can be easily used with a classical commercial CE instrumentation and has great potential for application in areas where a large numbers of samples need to be analyzed (pharmaceutical research and clinical diagnostics). ${ }^{25,32-34}$

In the present work, $\mathrm{CE}-\mathrm{C}^{4} \mathrm{D}$ is explored to develop an ultra-fast method (around $35 \mathrm{~s}$ per analysis) for the simultaneous determination of NPZ and DIP, or NPZ and PHEN, or NPZ and CPHEN in three different samples.

\section{Experimental}

Deionized water (resistivity $\geq 18 \mathrm{M} \Omega \mathrm{cm}$ ) obtained from a Millipore Direct-Q3 water purification system (Bedford, MA, USA) was used to prepare all aqueous solutions. Acetonitrile and phosphoric acid (HPLC grade) were purchased from Merck (Darmstadt, Germany); 2-(morpholin-4-yl)ethane-1-sulfonic acid (MES), histidine (HIS) and $\mathrm{NaOH}$ from Vetec (Rio de Janeiro, RJ, Brazil) and naphazoline hydrochloride (NPZ), diphenhydramine hydrochloride (DIP), pheniramine (PHEN), chlorpheniramine (CPHEN), 2-(cyclohexylamino) ethanesulfonic acid (CHES), triethanolamine (TEA) and 3,4-dimethoxycinnamic acid (DMX) from Sigma-Aldrich (Milwaukee, WI, USA). All reagents were used without further purification. NPZ, DIP, PHEN and CPHEN stock solution was freshly prepared just before the experiments by dissolution in deionized water.

Three pharmaceutical samples with different compositions were purchased from local drug stores: (i) 0.5 and $1.0 \mathrm{mg} \mathrm{mL}^{-1}$ of NPZ and DIP, respectively; (ii) 0.25 and $3.0 \mathrm{mg} \mathrm{mL}^{-1}$ of NPZ and PHEN, respectively; (iii) 0.5 and $0.5 \mathrm{mg} \mathrm{mL}^{-1}$ of NPZ and CPHEN, respectively. The excipients of nasal spray solution $(i)$ are benzalkonium chloride, rose essence, and sodium chloride. The excipients of eye drops ( $i i$ and $i i i)$ consisted of boric acid, sodium borate, sodium chloride, disodium edetate and benzalkonium chloride. Samples were simply diluted in water before analysis.

\section{CE measurements}

Electrophoresis separations were performed in a homemade CE equipment with two compact and highresolution capacitively coupled contactless conductivity detectors $\left(C^{4} \mathrm{D}\right){ }^{18,35}$ The detectors were positioned along the capillary at $10 \mathrm{~cm}$ from each end. The fused-silica capillary used in all experiments was $50 \mathrm{~cm}$ long (effective lengths of 10 and $40 \mathrm{~cm}$ ) and $50 \mu$ i.d. $\times 375 \mu \mathrm{m}$ o.d. (Agilent, Folsom, CA, USA). The capillary was daily flushed with deionized water for $10 \mathrm{~min}$ before use, followed by $0.1 \mathrm{~mol} \mathrm{~L}^{-1} \mathrm{NaOH}$ for $10 \mathrm{~min}$, again with deionized water for $10 \mathrm{~min}$ and finally with BGE for $10 \mathrm{~min}$. The samples were hydrodynamically injected for $1.25 \mathrm{~s}$ at $25 \mathrm{kPa}$. All experiments were carried out at $+25 \mathrm{kV}$ (inlet side) using normal electroosmotic flow (EOF) mode (towards the cathode).

\section{Reference procedure}

The HPLC measurements were performed using a Shimadzu LC-20A Prominence (Fukushima, Japan) equipped with a diode array detector (SPD-M20A), an LC column (Phenomenex 110 Å Gemini-C18, $150 \times 4.6 \mathrm{~mm}$, $5 \mu \mathrm{m}$, Torrance, CA, USA), an auto sampler (SIL 10-AF; injection volume of $50 \mu \mathrm{L}$ ) and two pumps (LC-6AD-VP). The mobile phase consisted of a mixture $(55: 45, \mathrm{v} / \mathrm{v})$ of methanol and $0.1 \mathrm{~mol} \mathrm{~L}^{-1} \mathrm{H}_{3} \mathrm{PO}_{4}$ ( $\mathrm{pH}$ adjusted to 7.0 with triethylamine). Three wavelengths were used for the detection of the species: 210 (DIP), 262 (PHEN and CPHEN) and $281 \mathrm{~nm}$ (NPZ). The flow rate was $1.0 \mathrm{~mL} \mathrm{~min}^{-1} .36$

\section{Results and Discussion}

In this study, the target compounds are weak bases (NPZ, $\mathrm{p} K_{\mathrm{a}}=10.2 ;$ DIP, $\mathrm{p} K_{\mathrm{a}}=8.9$; both PHEN and CPHEN, $\mathrm{p} K_{\mathrm{a}_{1}}=3.6$ and $\left.\mathrm{p} K_{\mathrm{a}_{2}}=9.5\right)$ and, therefore, can exist in cationic forms in aqueous solutions. ${ }^{37}$ The chemical structures of the evaluated compounds are shown in Figure 1.

The initial intention was the determination of the four molecules in a single run, however, the similar mobilities of PHEN and CPHEN in the $\mathrm{pH}$ range (3 to 12) commonly used in capillary zone electrophoresis prevent their quick separation. However, all these active ingredients are not found in the same pharmaceutical formulation. The following mixtures are found in commercial products: (i) NPZ + DIP; (ii) NPZ + PHEN, and (iii) NPZ + CPHEN. Hence, efforts were made to identify a single BGE that allows the separation and detection of the target compounds in these samples.

The first BGE evaluated in this study was based on a previously optimized method for fast and simultaneous 
(a)<smiles>c1ccc2c(CC3=NCCN3)cccc2c1</smiles>

(c)<smiles>CN(C)CCC(c1ccccc1)c1ccccn1</smiles><smiles>CN(C)CC(COC(c1ccccc1)c1ccccc1)N(C)C</smiles>

(d)<smiles>CN1CCC1C(CC1CCCN1)c1ccccn1</smiles>

Figure 1. Chemical structures and $\mathrm{p} K_{\mathrm{a}}$ values of (a) naphazoline (NPZ); (b) diphenhydramine (DIP); (c) pheniramine (PHEN) and (d) chlorpheniramine (CPHEN). Only the fully protonated forms are shown.

determination of NPZ and zinc ( $20 \mathrm{mmol} \mathrm{L}^{-1}$ of MES/HIS; $\mathrm{pH}=6.0) .{ }^{26}$ Figure 2 shows the electropherograms obtained with the injection of two sample solutions suitably diluted in water (nasal spray solution and eye drops).

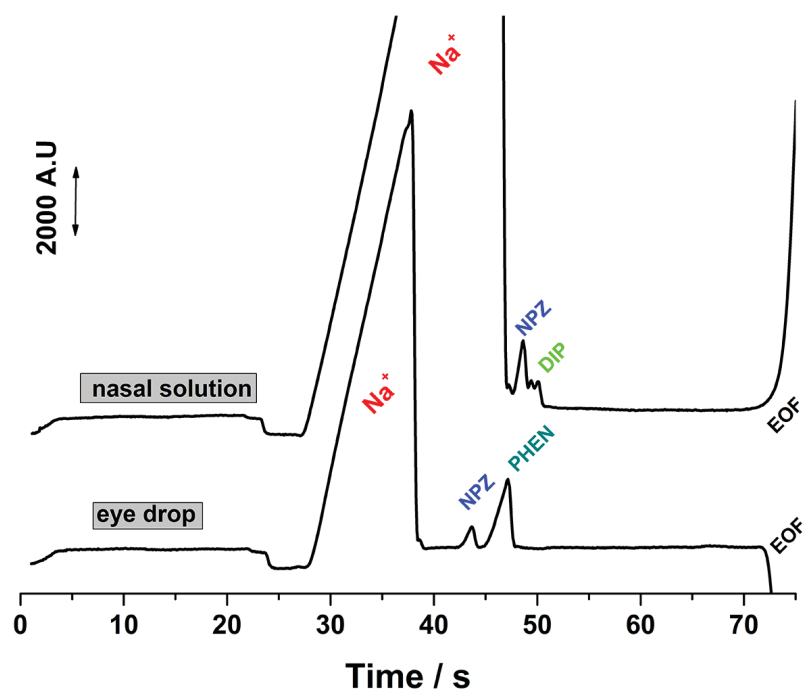

Figure 2. Electropherograms of two sample solutions (nasal and eye drops) diluted two times in water. Background electrolyte (BGE): $20 \mathrm{mmol} \mathrm{L}^{-1}$ of MES/HIS (2-(morpholin-4-yl)ethane-1-sulfonic acid/ histidine; $\mathrm{pH}=6.0$ ). Column: fused silica capillary with total and effective length of 50 and $10 \mathrm{~cm}$, respectively; internal diameter: $50 \mu \mathrm{m}$; separation voltage: $+25 \mathrm{kV}$ (inlet site); hydrodynamic injection: $25 \mathrm{kPa}$ for $1.5 \mathrm{~s}$.

As can be observed in Figure 2, in addition to the active ingredients NPZ + PHEN (eye drops) and NPZ + DIP (nasal drops), both samples contain $\mathrm{Na}^{+}$as excipient. In the eye drop sample, an adequate resolution between the excipient $\left(\mathrm{Na}^{+}\right)$and the analytes (NPZ and PHEN) was obtained. However, the concentration of $\mathrm{Na}^{+}$in the nasal

spray sample is much higher and no adequate resolution between the peaks of $\mathrm{Na}^{+}$and the active ingredients (NPZ and DIP) was achieved.

In order to achieve better resolution between these target analytes and $\mathrm{Na}^{+}$, different BGE compositions were evaluated. In order to obtain BGEs with similar mobility (conductivity) to $\mathrm{Na}^{+}, \mathrm{NaOH}$ was added to weak acid solutions and the $\mathrm{pH}$ adjusted to values close to their respective $\mathrm{p} K_{\mathrm{a}}$ (maximum buffer capacity). Thus, the presence of $\mathrm{Na}^{+}$will no longer be detected by the $\mathrm{C}^{4} \mathrm{D}$. Different BGEs composition commonly employed in capillary zone electrophoresis ${ }^{38}$ were evaluated (Figure S1, Supplementary Information section): (S1a) $10 \mathrm{mmol} \mathrm{L}^{-1}$ boric acid with pH-adjusted to 9.5 with $\mathrm{NaOH}$; (S1b) $20 \mathrm{mmol} \mathrm{L}^{-1}$ MES with $\mathrm{pH}$-adjusted to 6.0 with $\mathrm{NaOH}$; (S1c) $50 \mathrm{mmol} \mathrm{L}^{-1}$ CHES with pH-adjusted to 8.5 with $\mathrm{NaOH}$; (S1d) $20 \mathrm{mmol} \mathrm{L}^{-1}$ CHES with $\mathrm{pH}$-adjusted to 8.5 with $\mathrm{NaOH}$; (S1e) $12 \mathrm{mmol} \mathrm{L}^{-1} \mathrm{TEA}+10 \mathrm{mmolL}^{-1} \mathrm{DMX}$ with $\mathrm{pH}$-adjusted to 8.5 with $\mathrm{NaOH}$; (S1f) $20 \mathrm{mmol} \mathrm{L}^{-1} \mathrm{HIS}+10 \mathrm{mmol} \mathrm{L}^{-1}$ DMX with $\mathrm{pH}$-adjusted to 9.5 with $\mathrm{NaOH}$. Best performance was achieved with the BGE composed by HIS and DMX and $\mathrm{pH}$-adjusted to 9.5 with $\mathrm{NaOH}$ (Figure S1f). The electropherograms obtained with this buffer showed good resolution $(\mathrm{r}>1.4)$ among the target analytes and nointerference of $\mathrm{Na}^{+}$(inactive excipient). The performance of the selected buffer can be better observed in Figure 3, which shows electropherograms for three different solutions: (a) standard solution containing $500 \mu \mathrm{mol} \mathrm{L} \mathrm{L}^{-1}$ $\mathrm{NPZ}+250 \mu \mathrm{mol} \mathrm{L}^{-1} \mathrm{DIP}$; (b) same standard solution spiked with $50 \mu \mathrm{mol} \mathrm{L}^{-1}$ benzalkonium chloride and $10 \mathrm{mmol} \mathrm{L}^{-1}$ $\mathrm{NaCl}$; (c) nasal spray sample solution 8-fold diluted in water.

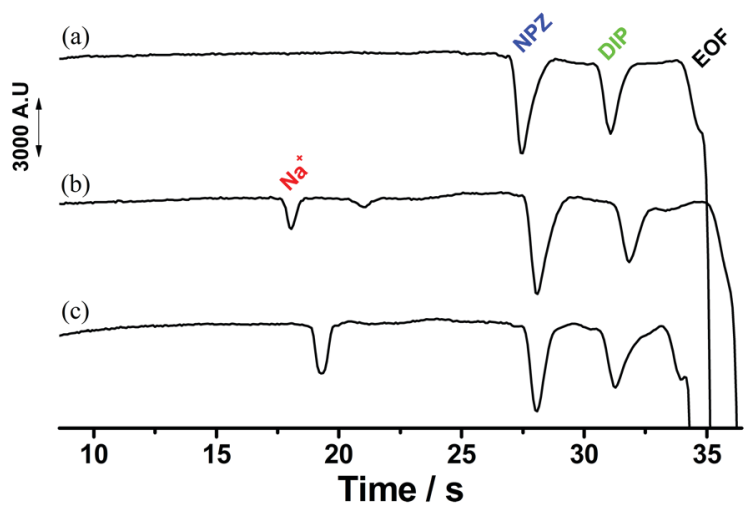

Figure 3. Electropherograms obtained from three different solutions: (a) standard solution containing $500 \mu \mathrm{mol} \mathrm{\textrm {L } ^ { - 1 }}$ of naphazoline (NPZ) and $250 \mu \mathrm{mol} \mathrm{L}^{-1}$ DIP (diphenhydramine); (b) same standard solution spiked with $50 \mu \mathrm{mol} \mathrm{L} \mathrm{L}^{-1}$ of benzalkonium chloride and $10 \mathrm{mmol} \mathrm{L}^{-1}$ of sodium chloride; (c) nasal sample solution 8-fold diluted; background electrolyte (BGE): $20 \mathrm{mmol} \mathrm{L}^{-1} \mathrm{HIS}$ (histidine) $+10 \mathrm{mmol} \mathrm{L}^{-1} \mathrm{DMX}$ (3,4-dimethoxycinnamic acid) with $\mathrm{pH}$ adjusted to 9.5 with $\mathrm{NaOH}$; Effective capillary length: $10 \mathrm{~cm}$; separation voltage: $+25 \mathrm{kV}$ (inlet site); hydrodynamic injection: $25 \mathrm{kPa}$ for $1.25 \mathrm{~s}$. 
The presence of high concentrations of $\mathrm{Na}^{+}$and benzalkonium chloride as excipients did not affect the resolution between the analyte peaks once similar electropherograms were observed in the absence (Figure 3a) and in the presence (Figure 3b) of the excipients. Finally, an electropherogram for a real nasal spray sample diluted in water (Figure 3c) was also carried out and the obtained result also leads to similar conclusion.

Some instrumental parameters such as separation voltage, injection time (at $25 \mathrm{kPa}$ ), temperature, and effective capillary length were also evaluated in order to obtain the optimal separation conditions. The best values were selected to achieve the best selectivity (resolution), good peak shape, sensitivity, minimal Joule effect (low currents), and shortest analysis time. Table 1 summarizes the evaluated ranges and the selected instrumental parameters of the proposed CE- $\mathrm{C}^{4} \mathrm{D}$ method.

The precision of the proposed method was evaluated by ten consecutive runs of standard solutions with similar composition of the three commercially available samples (Figure 4). The results obtained for each standard solution in the same day and with the same capillary column length were considered as intra-day precision. The results
Table 1. Optimized conditions for the proposed $\mathrm{CE}-\mathrm{C}^{4} \mathrm{D}$ procedure

\begin{tabular}{lcc}
\hline Parameter & $\begin{array}{c}\text { Evaluated } \\
\text { range }\end{array}$ & $\begin{array}{c}\text { Optimized } \\
\text { value }\end{array}$ \\
\hline BGE concentration / $\left(\mathrm{mmol} \mathrm{L}^{-1}\right)$ & $15-30$ & 20 \\
Separation voltage $/ \mathrm{kV}$ & $15-25$ & 25 \\
Injection time at $25 \mathrm{kPa} / \mathrm{s}$ & $0.5-1.5$ & 1.25 \\
Temperature $/{ }^{\circ} \mathrm{C}$ & $20-30$ & 25 \\
$\mathrm{pH}$ of BGE & $9.0-10.2$ & 9.5 \\
Effective capillary length / cm & 10 and 40 & 10 \\
\hline
\end{tabular}

BGE: background electrolyte.

obtained for each standard solution in different days and with different column lengths $(50 \pm 3 \mathrm{~cm})$ were considered as inter-day precision (Table 2).

Intra-day repeatability was below 3.5, 3.2 and $2.4 \%$ for NPZ and DIP, NPZ and PHEN, NPZ and CPHEN analysis, respectively. Inter-day repeatability was below $7.8 \%$ for all analytes. Linear response ranges were established considering correlation coefficients above 0.99 and the active ingredients concentration ratio in the samples. The results obtained in these studies and other analytical features are summarized in Table 2.
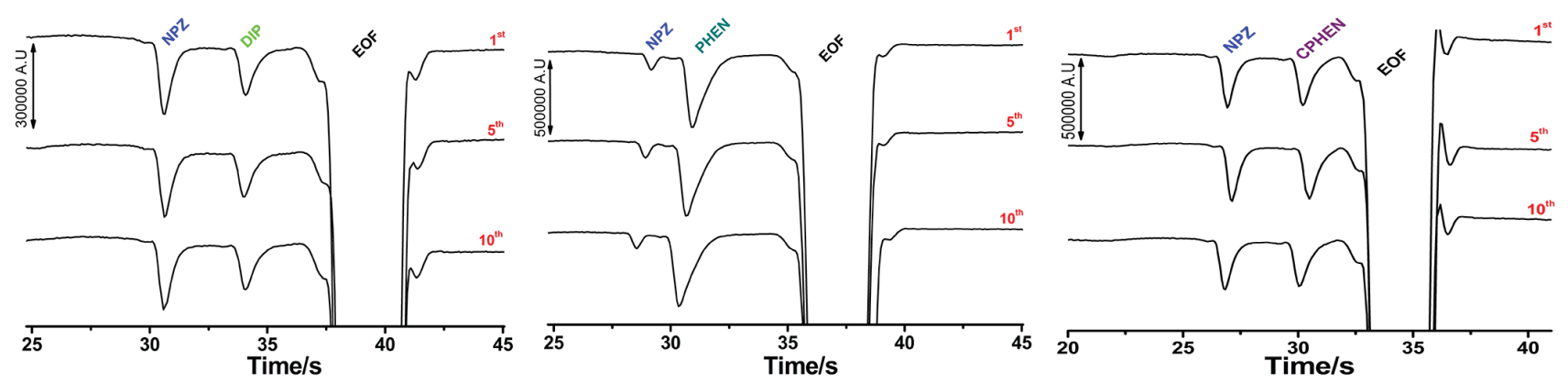

Figure 4. Electropherograms obtained for ten successive injections of a standard solution containing: (left) NPZ (naphazoline) and DIP (diphenhydramine) (500 and $\left.250 \mu \mathrm{mol} \mathrm{L}^{-1}\right)$; (middle) NPZ and PHEN (pheniramine) $\left(100\right.$ and $\left.840 \mu \mathrm{mol} \mathrm{L}^{-1}\right)$; (right) NPZ and CPHEN (chlorpheniramine) $\left(500\right.$ and $\left.313 \mu \mathrm{mol} \mathrm{L}{ }^{-1}\right)$. For other conditions, see Figure 2.

Table 2. Analytical features of the proposed CE-C ${ }^{4} \mathrm{D}$ procedure (confidence interval $=95 \%$ )

\begin{tabular}{lccc}
\hline Analytical feature & NPZ / DIP & NPZ / PHEN & NPZ / CPHEN \\
\hline Migration time / s & $32.4 \pm 0.2 / 34.2 \pm 0.1$ & $29.3 \pm 1.2 / 31.1 \pm 1.1$ & $29.9 \pm 1.2 / 30.3 \pm 1.1$ \\
Resolution & $2.3 \pm 0.1 / 1.8 \pm 0.1$ & $1.4 \pm 0.1 / 2.3 \pm 0.1$ & $2.1 \pm 0.1 / 1.6 \pm 0.1$ \\
Correlation coefficient & $0.999 / 0.999$ & $0.998 / 0.997$ & $0.999 / 0.999$ \\
Linear range / $\left(\mu \mathrm{mol} \mathrm{L}^{-1}\right)$ & $100-1600 / 50-800$ & $90-250 / 760-2100$ & $80-500 / 50-313$ \\
$\mathrm{LOD} /\left(\mu \mathrm{mol} \mathrm{L}^{-1}\right)$ & $25 / 25$ & $25 / 25$ & $25 / 13$ \\
$\mathrm{LOQ} /\left(\mu \mathrm{mol} \mathrm{L}^{-1}\right)$ & $83 / 83$ & $83 / 83$ & $83 / 43$ \\
Intra-day RSD $(\mathrm{n}=10) / \%$ & $3.5 / 2.3$ & $3.2 / 2.2$ & $2.4 / 1.5$ \\
Inter-day RSD $(\mathrm{n}=3) / \%$ & $4.3 / 7.8$ & $2.2 / 6.8$ & $3.0 / 4.7$ \\
Analytical frequency / (injections per $\mathrm{h})$ & 105 & 115 & 118
\end{tabular}

NPZ: naphazoline; DIP: diphenhydramine; PHEN: pheniramine; CPHEN: chlorpheniramine; LOD: limit of detection; LOQ: limit of quantification; RSD: relative standard deviation. 
Table 3. Results obtained by HPLC and by the proposed CE-C ${ }^{4} \mathrm{D}$ method

\begin{tabular}{|c|c|c|c|c|c|c|}
\hline \multirow{2}{*}{ Sample } & & \multirow{2}{*}{$\begin{array}{l}\text { Label value / } \\
\left(\mathrm{mg} \mathrm{mL}^{-1}\right)\end{array}$} & \multirow{2}{*}{$\begin{array}{c}\mathrm{CE} / \\
\left(\mathrm{mg} \mathrm{mL}^{-1}\right)\end{array}$} & \multirow{2}{*}{$\begin{array}{c}\text { HPLC / } \\
\left(\mathrm{mg} \mathrm{mL}^{-1}\right)\end{array}$} & \multicolumn{2}{|c|}{ Error $/ \%$} \\
\hline & & & & & $\mathrm{E}_{1}$ & $\mathrm{E}_{2}$ \\
\hline \multirow[t]{2}{*}{$\bar{A} 1$} & NPZ & 1.00 & $0.930 \pm 0.030$ & $0.981 \pm 0.020$ & -7.0 & -5.1 \\
\hline & DIP & 0.50 & $0.430 \pm 0.025$ & $0.410 \pm 0.011$ & -14.0 & +4.6 \\
\hline \multirow[t]{2}{*}{ A2 } & NPZ & 1.00 & $0.922 \pm 0.037$ & $0.931 \pm 0.018$ & -7.8 & -1.0 \\
\hline & DIP & 0.50 & $0.430 \pm 0.024$ & $0.400 \pm 0.007$ & -14.0 & +7.0 \\
\hline \multirow[t]{2}{*}{ A3 } & NPZ & 0.25 & $0.269 \pm 0.018$ & $0.270 \pm 0.003$ & +7.6 & -0.4 \\
\hline & PHEN & 3.00 & $3.366 \pm 0.138$ & $3.255 \pm 0.019$ & +12.2 & +3.3 \\
\hline \multirow[t]{2}{*}{ A4 } & NPZ & 0.25 & $0.259 \pm 0.023$ & $0.273 \pm 0.016$ & +3.5 & -5.1 \\
\hline & PHEN & 3.00 & $3.216 \pm 0.085$ & $3.045 \pm 0.006$ & +7.2 & +5.3 \\
\hline \multirow[t]{2}{*}{ A5 } & NPZ & 0.5 & $0.465 \pm 0.046$ & $0.430 \pm 0.012$ & -7.0 & +8.0 \\
\hline & CPHEN & 0.5 & $0.460 \pm 0.027$ & $0.433 \pm 0.022$ & -8.0 & +6.0 \\
\hline \multirow[t]{2}{*}{ A6 } & NPZ & 0.5 & $0.455 \pm 0.027$ & $0.423 \pm 0.011$ & -9.0 & +7.0 \\
\hline & CPHEN & 0.5 & $0.450 \pm 0.040$ & $0.432 \pm 0.015$ & -10.0 & +4.0 \\
\hline
\end{tabular}

CE: capillary electrophoresis; HPLC: high-performance liquid chromatography; $\mathrm{E}_{1}$ : difference between results obtained by CE-C ${ }^{4} \mathrm{D}$ (capillary electrophoresis with capacitively coupled contactless conductivity detection) and the values reported in the label; $\mathrm{E}_{2}$ : difference between results obtained by $\mathrm{CE}-\mathrm{C}^{4} \mathrm{D}$ and by the reference procedures (HPLC); NPZ: naphazoline; DIP: diphenhydramine; PHEN: pheniramine; CPHEN: chlorpheniramine.

The accuracy of the proposed $C E-C^{4} \mathrm{D}$ method was evaluated by the analysis of six pharmaceutical samples. The obtained results were compared to those obtained by HPLC (Table 3).

The results obtained by the proposed $\mathrm{CE}-\mathrm{C}^{4} \mathrm{D}$ method were in agreement with those obtained by HPLC. The calculated $t$ values (paired Student's $t$-test) were smaller than the critical value $(2.78, n=3)$, which indicates that there are no significant differences between the results obtained by both methods ( $95 \%$ confidence level). The performance of the $\mathrm{CE}-\mathrm{C}^{4} \mathrm{D}$ method was also estimated by recovery studies. Pharmaceutical samples were analyzed before and after addition of known amounts of the target analytes. All recovery values ranged from 96 to $103 \%$ with relative standard deviation between 2 and 4\%, which indicates the absence of sample-matrix effects.

The proposed CE method has higher limits of detection compared to HPLC, ${ }^{11}$ which may be considered a disadvantage for analysis of samples with low concentrations of the target molecules. However, in pharmaceutical sample analysis, low limits of detection are usually not required. In addition, the proposed CE-C ${ }^{4} \mathrm{D}$ method is ca. ten times faster than HPLC, less expensive (use of a simple homemade CE equipment), and significantly lower consumption of samples and reagents (green analytical method).

\section{Conclusions}

A simple, accurate and low-cost $\mathrm{CE}-\mathrm{C}^{4} \mathrm{D}$ method for fast determination of NPZ in the presence of DIP, PHEN or CPHEN was developed. The new $\mathrm{CE}-\mathrm{C}^{4} \mathrm{D}$ method have several desirable features, such as short analysis time ( $35 \mathrm{~s}$ by sample), a simple sample preparation step (only dilution in water), and minimum waste generation by analysis (suitable for implementation in routine analysis). Additionally, excipients employed on the pharmaceutical formulation did not hindered analytes resolution, improving selectivity. Thereby, the proposed method is a suitable alternative to chromatographic methods for pharmaceuticals quality control.

\section{Supplementary Information}

Electropherograms obtained for standard and sample solutions in different BGEs are shown in Figure S1. This material is available free of charge at http://jbcs.sbq.org.br as PDF file.

\section{Acknowledgments}

The authors are grateful to CAPES (PRO FORENSES, process number: 23038.007073/2014-12) and FAPEMIG (APQ-02118-15) for the financial support. E. M. R. (process number: 307333/2014-0) and R. A. A. M. (process number: 308174/2013-5) thank CNPQ for fellowships.

\section{References}

1. Musshoff, F.; Gerschlauer, A.; Madea, B.; Forensic Sci. Int. 2003, 134, 234. 
2. Díaz, B. C.; Terrones, S. C.; Fernández, J. M. C.; Carretero, A. S.; Gutiérrez, A. F.; Anal. Bioanal. Chem. 2004, 379, 30.

3. Fukushima, H.; Norimoto, K.; Seki, T.; Nishiguchi, T.; Nakamura, T.; Konobu, T.; Nishio, K.; Okuchi, K.; Clin. Toxicol. 2008, 46, 254.

4. Pragst, F.; Herre, S.; Bakdash, A.; Forensic Sci. Int. 2006, 161, 189.

5. Lordi, N. G.; Christian, J. E.; J. Am. Pharm. Assoc., Sci. Ed. 1956, 45, 300.

6. Karaman, K.; Bostanci, E. B.; Aksoy, E.; Ulas, M.; Yigit, T.; Erdemli, M. O.; Ercin, U.; Bilgihan, A.; Saydam, G.; Akoglu, M.; Am. J. Surg. 2013, 205, 213.

7. Tosti, A.; Bardazzi, F.; Piancastell, E.; Contact Dermatitis 1990, 22,55 .

8. Ali, N. W.; Hegazy, M. A.; Abdelkawy, M.; Abdelfatah, R. M.; Pak. J. Pharm. Sci. 2013, 26, 641.

9. Simasek, M.; Blandino, D. A.; Am. Fam. Physician 2007, 75, 515.

10. Simons, F. E. R.; Am. J. Med. 2002, 113, 38.

11. Huang, T.; Chen, N.; Wang, D.; Lai, Y.; Cao, Z.; Chem. Cent. J. 2014, 8, 7 .

12. Marchesini, A. F.; Williner, M. R.; Mantovani, V. E.; Robles, J. C.; Goicoechea, H. C.; J. Pharm. Biomed. Anal. 2003, 31, 39.

13. Santoni, G.; Mura, P.; Pinzauti, S.; Gratteri, P.; Porta, E. L.; Int. J. Pharm. 1989, 50, 75.

14. Korany, M. A.; Bedair, M. M.; El-Gindy, A.; Drug Dev. Ind. Pharm. 1990, 16, 1555.

15. Shoukrallah, I.; Anal. Lett. 1991, 24, 2043.

16. Soliman, S. A.; Abdine, H.; Morcos, M. G.; Can. J. Pharm. Sci. 1976, 11, 63 .

17. Kelani, K. M.; J. AOAC Int. 1998, 81, 1128.

18. Zemann, A. J.; Schnell, E.; Volgger, D.; Bonn, G. K.; Anal. Chem. 1998, 70, 563.

19. da Silva, J. A. F.; do Lago, C. L.; Anal. Chem. 1998, 70, 4339.

20. Terabe, S.; Otsuka, K.; Ichikawa, K.; Tsuchiya, A.; Ando, T.; Anal. Chem. 1984, 56, 111.
21. Kubáň, P.; Hauser, P. C.; Electrophoresis 2009, 30, 176.

22. Brito-Neto, J. G. A.; da Silva, J. A. F.; Blanes, L.; do Lago, C. L.; Electroanalysis 2005, 17, 1207.

23. Breadmore, M. C.; Wuethrich, A.; Li, F.; Phung, S. C.; Kalsoom, U.; Cabot, J. M.; Tehranirokh, M.; Shallan, A. I.; Abdul Keyon, A. S.; See, H. H.; Dawod, M.; Quirino, J. P.; Electrophoresis 2017, 38, 33.

24. Kubáň, P.; Hauser, P. C.; Anal. Chim. Acta 2008, 607, 15.

25. Marra, M. C.; Cunha, R. R.; Vidal, D. T. R.; Muñoz, R. A. A.; do Lago, C. L.; Richter, E. M.; J. Chromatogr. A 2014, 1327, 149.

26. Ribeiro, M. M. A. C.; Oliveira, T. C.; Batista, A. D.; Muñoz, R. A. A.; Richter, E. M.; J. Chromatogr. A 2016, 1472, 134.

27. Cunha, R. R.; Gimenes, D. T.; Muñoz, R. A. A.; do Lago, C. L.; Richter, E. M.; Electrophoresis 2013, 34, 1423.

28. Zemann, A. J.; Electrophoresis 2003, 24, 2125.

29. Marra, M. C.; Silva, P. L.; Muñoz, R. A. A.; Richter, E. M.; J. Braz. Chem. Soc. 2014, 25, 913.

30. Melanson, J. E.; Lucy, C. A.; J. Chromatogr. A 2000, 884, 311.

31. Glatz, Z.; Electrophoresis 2013, 34, 631.

32. Micke, G. A.; Costa, A. C. O.; Heller, M.; Barcellos, M.; Piovezan, M.; Caon, T.; de Oliveira, M. A. L.; J. Chromatogr. A 2009, 1216, 7957.

33. Ribeiro, M. M. A. C.; Freitas, J. M.; Muñoz, R. A. A.; do Lago, C. L.; Richter, E. M.; Anal. Methods 2016, 8, 4432.

34. Valese, A. C.; Spudeit, D. A.; Dolzan, M. D.; Bretanha, L. C.; Vitali, L.; Micke, G. A.; J. Anal. Methods Chem. 2016, 2016, 1.

35. Brito-Neto, J. G. A.; da Silva, J. A. F.; Blanes, L.; do Lago, C. L.; Electroanalysis 2005, 17, 1198.

36. Sayed, N. E. D.; Hegazy, M.; Abdelkawy, M.; Abdelfatah, R.; Bull. Fac. Pharm. (Cairo Univ.) 2013, 51, 57.

37. Swain, M.; J. Chem. Inf. Model. 2012, 52, 613.

38. Jaroš, M.; Hruška, V.; Štědrý, M.; Zusková, I.; Gaš, B.; Electrophoresis 2004, 25, 3080.

Submitted: January 4, 2018 Published online: April 3, 2018 